Note: This is a pre-copy-editing, author-produced PDF of an article accepted for publication in Addiction following peer review. The definitive publisher-authenticated version [Smyth BP, Keenan E and O'Connor JJ (1998) Bloodborne viral infection in Irish injecting drug users, Addiction, 93(11), 1649-1656] is available online at http://www3.interscience.wiley.com/journal/117967480/toc

\title{
Bloodborne viral infection in Irish injecting drug users
}

\author{
Prevalence of hepatitis C, hepatitis B and HIV among new \\ attenders to the Trinity Court Drug Treatment Centre, Dublin, \\ between September 1992 and September 1997.
}

Bobby P. Smyth, Eamon Keenan, John J. O'Connor

The Drug Treatment Centre, Trinity Court, 30/31 Pearse St. Dublin 2, Ireland.

Correspondence: Dr. Bobby Smyth, Research Registrar, 15 City Gate, Saint Augustine St., Dublin 8, Ireland.

Total number of pages - 15pages

Word count ( for text $\&$ references)-2426 words

Word Count ( Excluding references ) 1888 (previously 2094) 


\section{Introduction}

World-wide, injecting drug users ( IDU) represent a high risk group for bloodborne viral infections, including $\mathrm{HIV}^{1}$, hepatitis B ( $\left.\mathrm{HBV}\right)^{2}$ and hepatitis $\mathrm{C}(\mathrm{HCV})^{3}$. Harm reduction strategies ${ }^{4}$ have been advocated in order to prevent spread of bloodborne viral infection and many believe that these approaches have contributed to a reduced incidence of HIV ${ }^{5,6}$. There is only limited evidence that needle exchange attendance is associated with a reduction in $\mathrm{HCV}$ and $\mathrm{HBV}$ infections ${ }^{7}$. A recent study of the incidence of HCV infection among IDU failed to find a reduction in those who attended for methadone maintenance therapy ${ }^{8}$. There is a concern that current approaches may not be adequate to reduce the occurrence of unsafe injecting practices to a sufficiently low level to ensure a low incidence of $\mathrm{HCV}$ in populations of IDU where the prevalence of $\mathrm{HCV}$ is already $\operatorname{high}^{3}$. It is possible for harm reduction programmes to appear effective by minimising new cases of HIV while having little impact on HCV.

In Dublin harm reduction strategies have been in existence since 1989. These services have vastly expanded in the 1990's. The number of official needle exchange centres in the city has grown from one to 12 since 1990, the number of community outreach workers has trebled in the same period and access to methadone treatment has improved with the addition of four new addiction treatment centres and 12 satellite clinics. Trinity Court is the largest and longest established treatment centre in Dublin. Referrals are accepted from all areas of the city. New attenders tend to present early in their injecting careers. Patients with a history of injecting are encouraged to agree to screening tests for $\mathrm{HIV}, \mathrm{HBV}$ and $\mathrm{HCV}$. We sought to measure the prevalences of these viral infections against the background of the expanding harm reduction programme. 


\section{Methods}

Since September 1992, data has been recorded on an ongoing basis on all new attenders who were IDU and tested for anti-HCV. When available, the results of screening tests for HBV and HIV were included. A doctor (BS), who was blind to the test results, obtained socio-demographic details and some drug use characteristics from the medical notes of the initial assessment interview. The variables chosen for inclusion were those found to be most frequently and reliably recorded in a pilot study prior to commencement of this project. Data was incomplete in only 28 cases (3.8\%). We report here the results of the first five years of this data collection.

\section{Viral markers}

Prior to July 1993, the screening test for HCV was a second generation enzyme linked immunosorbant assay (EIA) for anti-HCV ( Ortho Diagnostics, Amersham, Buckinghamshire, England ). Subsequently, the third generation EIA was used. All positive results were confirmed with an additional EIA. A recombinant immunoblot assay was used in situations where the two EIA gave contradictory results. The screening test for HBV was an EIA for hepatitis B surface antigen. The initial screen for HIV was with two EIA tests for antibody to HIV. Positive tests were confirmed with the Western blot assay.

\section{Statistical methods}

Confidence intervals were calculated by using exact methods for proportions. Analytical techniques included Pearson's chi squared test and Fisher's exact test statistic to determine the significance of associations for categorical variables. For ordered categorical variables the Mantel-Haenszel chisquared test for linear trend was used. Odds ratios and their $95 \%$ confidence intervals were used to describe the relationship between subject characteristics and serology results. The Student's t-test 
was used for difference in the means of continuous variables except the Mann-Whitney U-test was performed when the distribution of a continuous variable was skewed. For $\mathrm{HCV}$, multivariate analyses were performed using logistic regression and variables found to be significant on univariate analyses were entered into the regression equation ${ }^{9}$.

\section{Results}

Of 733 attenders, 453 were anti-HCV positive ( $61.8 \%, 95 \%$ confidence interval $58.3-65.3 \%$ ). Table 1 presents the relationship between anti-HCV and the socio-demographic and drug use variables. Older age, longer history of injecting, commencement of injecting prior to 1990 and daily drug expenditure of over Ir£65 were each significantly associated with increased risk. There was a tendency for unemployed attenders to be more likely to be anti-HCV positive (N.S.) and a similar tendency was observed in those who were in a sexual relationship with another IDU (N.S.). Figure 1 depicts the association between duration of injecting and HCV status. Multivariate analysis indicated that only longer history of injecting and daily drug expenditure of over $£ 65$ were independently associated with increased risk of $\mathrm{HCV}$. 


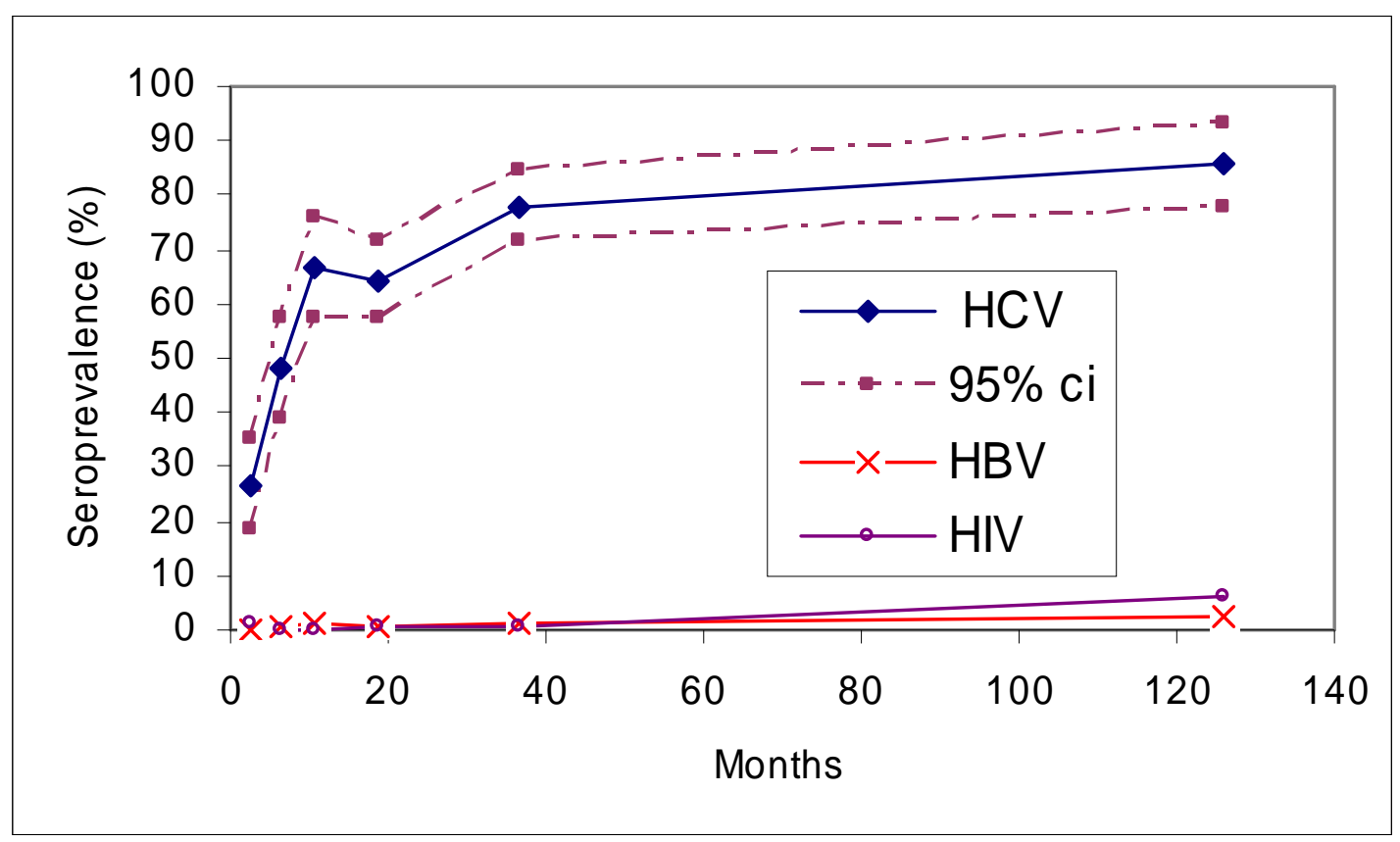

Figure 1. Prevalences of anti-HCV, hepatitis B surface antigen and HIV in serial cohorts with increasing time since onset of injecting (1-4 months, 5-8 months, 9-12 months, 13-24 months, 25-60 months and over 60 months, y-axis coordinate equates to the mean period since onset of injecting for each cohort): results from new attenders to the Trinity Court Drug Treatment Centre, Dublin, between September 1992 and September 1997.

The prevalence of HBsAg was 1.0\% ( 7/729, [95\% confidence interval 0.3\%-1.7\%] ). The only independent variable significantly associated with increased risk of HBV was a history of injecting prior to 1990 ( see table 2, due to the small number testing positive, categories were compressed). Those testing positive for HBsAg had longer injecting histories but this was not significant ( medians, 45.0 months $v 15.9$ months, Mann Whitney $\mathrm{U}$ test, $\mathrm{p}=0.08$ ) 
Table 1. Distribution of general characteristics and injecting drug use behaviours of new attenders to the Trinity Court Drug Treatment Centre, Dublin, between September 1992 and September 1997, by antiHCV prevalence. Univariate and logistic regression analysis of associations.

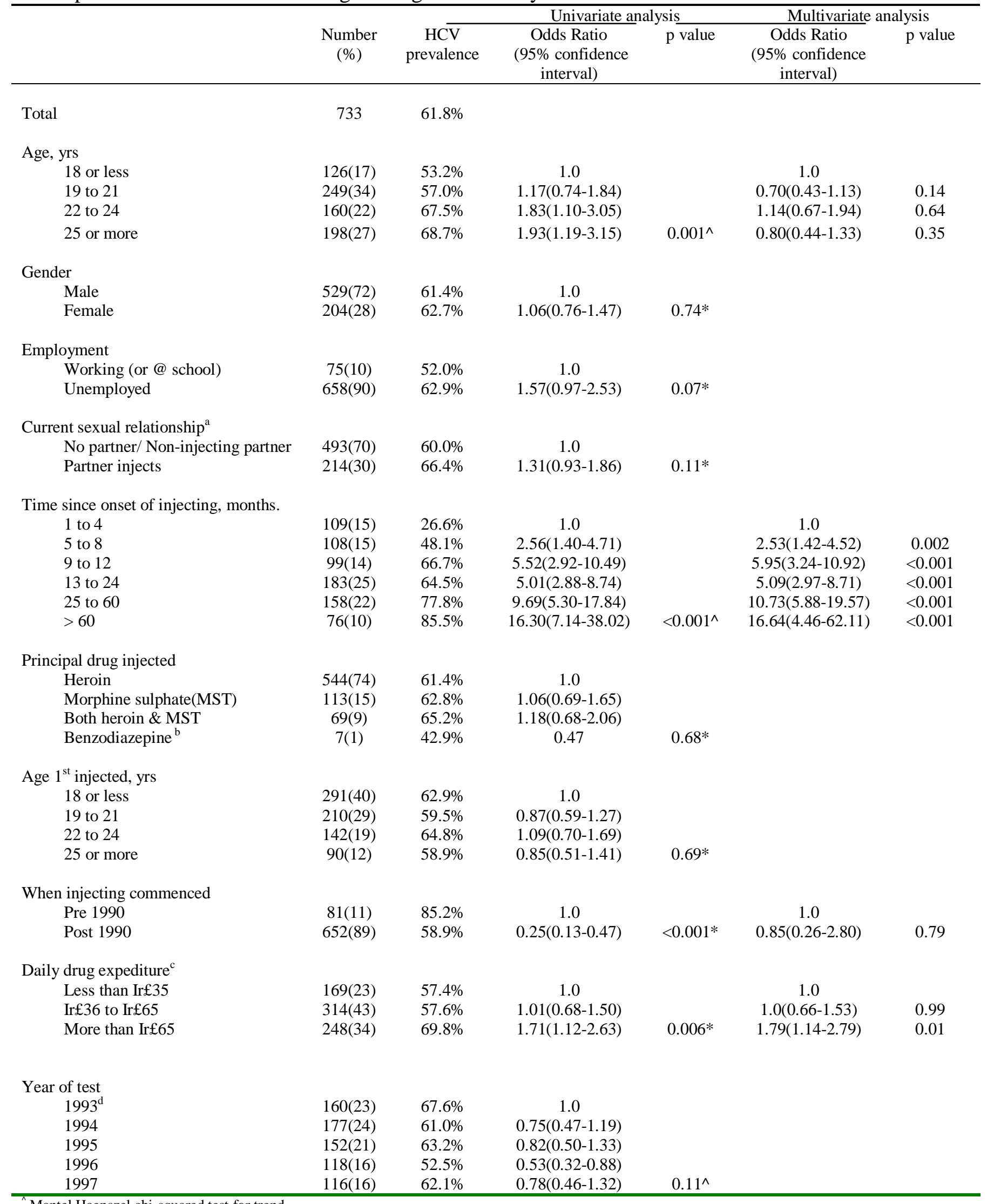

${ }^{\wedge}$ Mantel Haenszel chi-squared test for trend

* Pearson chi-squared test

${ }^{\mathrm{a}}$ Status of partner unknown in 26 cases.

${ }^{\mathrm{b}}$ Numbers using benzodiazapines too low to allow valid calculation of $95 \%$ confidence interval for odds ratio.

${ }^{\mathrm{c}}$ Daily drug expenditure unknown in 2 cases.

${ }^{\mathrm{d}}$ Includes 20 patients tested between September 1992 and December 1992. 
Table 2 General characteristics and injecting drug use behaviours of new attenders to the Trinity Court Drug Treatment Centre, Dublin, between September 1992 and September 1997, by HIV and hepatitis B surface antigen prevalences

\begin{tabular}{|c|c|c|c|c|c|c|}
\hline \multirow[b]{3}{*}{ Total } & \multicolumn{3}{|c|}{ HIV } & \multicolumn{3}{|c|}{ Hepatitis B sAg } \\
\hline & \multicolumn{2}{|c|}{$\begin{array}{l}\text { Proportion testing } \\
\text { positive }(\%)\end{array}$} & \multirow[t]{2}{*}{$\begin{array}{l}\text { Fisher's test } \\
\text { - p value }\end{array}$} & \multicolumn{2}{|c|}{$\begin{array}{l}\text { Proportion testing } \\
\text { positive }(\%)\end{array}$} & \multirow[t]{2}{*}{$\begin{array}{l}\text { Fisher's test - p } \\
\text { value }\end{array}$} \\
\hline & $7 / 600^{\mathrm{a}}$ & $(1.2)$ & & $7 / 729^{b}$ & $(1.0)$ & \\
\hline \multicolumn{7}{|l|}{ Age } \\
\hline 24 or less & $1 / 438$ & $(0.2)$ & & $4 / 533$ & $(0.8)$ & \\
\hline 25 or over & $6 / 162$ & $(3.7)$ & 0.002 & $3 / 196$ & $(1.5)$ & 0.39 \\
\hline \multicolumn{7}{|l|}{ Gender } \\
\hline Male & $5 / 432$ & $(1.2)$ & & $6 / 525$ & $(1.1)$ & \\
\hline Female & $2 / 168$ & $(1.2)$ & 1.0 & $1 / 204$ & $(0.05)$ & 0.68 \\
\hline \multicolumn{7}{|l|}{ Employment } \\
\hline Unemployed & $6 / 542$ & $(1.1)$ & & $6 / 655$ & $(0.9)$ & \\
\hline Working ( or @ school) & $1 / 58$ & $(1.7)$ & 0.51 & $1 / 74$ & $(1.4)$ & 0.53 \\
\hline \multicolumn{7}{|l|}{ Current sexual relationship } \\
\hline No partner/partner not injecting & $4 / 402$ & $(1.0)$ & & $5 / 491$ & $(1.0)$ & \\
\hline Partner injecting & $2 / 175$ & $(1.1)$ & 1.0 & $2 / 212$ & $(0.9)$ & 1.0 \\
\hline \multicolumn{7}{|l|}{ Time since $1^{\text {st }}$ injecting, years } \\
\hline Less than five years & $3 / 538$ & $(0.6)$ & & $5 / 654$ & $(0.8)$ & \\
\hline Five years or more & $4 / 62$ & $(6.5)$ & 0.003 & $2 / 75$ & $(2.7)$ & 0.16 \\
\hline \multicolumn{7}{|l|}{ Principal drug injected } \\
\hline Heroin & $7 / 457$ & $(1.5)$ & & $5 / 541$ & $(0.9)$ & \\
\hline Other & $0 / 143$ & $(0)$ & 0.20 & $2 / 188$ & $(1.1)$ & 1.0 \\
\hline \multicolumn{7}{|l|}{ Age $1^{\text {st }}$ injected } \\
\hline 24 or less & $5 / 525$ & $(1.0)$ & & $7 / 640$ & $(1.1)$ & \\
\hline 25 or more & $2 / 75$ & $(2.7)$ & 0.22 & $0 / 89$ & $(0)$ & 1.0 \\
\hline \multicolumn{7}{|l|}{ When injecting commenced } \\
\hline Pre 1990 & $4 / 64$ & $(6.3)$ & & $3 / 80$ & $(3.8)$ & \\
\hline Post 1990 & $3 / 536$ & $(0.6)$ & 0.003 & $4 / 649$ & $(0.6)$ & 0.03 \\
\hline \multicolumn{7}{|l|}{ Daily drug expenditure } \\
\hline Irf65 or less & $3 / 405$ & $(0.7)$ & & $3 / 481$ & $(0.6)$ & \\
\hline More than $\operatorname{Ir} £ 65$ & $4 / 194$ & $(2.1)$ & 0.22 & $4 / 246$ & $(1.6)$ & 0.23 \\
\hline \multicolumn{7}{|l|}{ Year of testing } \\
\hline 1992-1994 & $4 / 267$ & $(1.5)$ & & $5 / 342$ & $(1.5)$ & \\
\hline $1995-1997$ & $3 / 333$ & $(0.9)$ & 0.71 & $2 / 387$ & $(0.5)$ & 0.26 \\
\hline
\end{tabular}

${ }^{a}$ No HIV test was performed in 133 cases and the result was indeterminate in 2 cases.

${ }^{\mathrm{b}}$ No HBsAg test was conducted in 6 cases. 
The prevalence of HIV was $1.2 \%$ (7/600, [95\% confidence interval 0.3\%-2.0\%]). An injecting history of over five years, commencement of injecting prior to 1990 and age over 24 were each significantly associated with increased proportion testing positive for HIV ( see table 2 ). No test result was available in 133 cases and two results were indeterminate. Those reporting MST as their primary drug were underrepresented in the group tested for HIV ( Pearson's $x^{2}$ test, $\mathrm{p}=0.04$ ). No other independent variable was associated with uptake of HIV testing.

There was no significant association between any combination of the three viral markers.

\section{Discussion}

There are four possible areas of methodological concern in this study. Firstly, no data are presented on the reported frequency of unsafe injecting practices. Such practices are best examined via a standardised and detailed structured interview and possibly requiring an interviewer independent of treatment services ${ }^{10,11}$. Due to the long term nature of this ongoing study, there was no practical way of overcoming these obstacles and we therefore decided that no data on this area would be better than data of questionable reliability. Secondly, the daily drug expenditure was taken as a crude measure of daily drug use and injecting frequency. However, the 'street' price of heroin reduced by nearly $50 \%$ over the study period, falling to Ir£20 per 'quarter gram' in 1996-97. A third possible source of concern could be the change in the HCV screening test from a second generation to a third generation EIA early in the study period. Although the enhanced specificity of the third generation test substantially increases the 
positive predictive value of screening in very low prevalence populations such as blood donors, the change in positive predictive value in the high prevalence population studied here would be minimal ${ }^{12,13}$. Repeat examination of the data excluding those screened with the second generation test did not reveal any significant alteration in the reported findings on either univariate or multivariate analysis. Finally, there may be concern regarding possible selection bias in the HIV tested group as a substantial minority (18\%) of the study group were not screened for HIV. Importantly, those not tested did not differ significantly in terms of any of the variables demonstrated to be associated with bloodborne infection.

The variables significantly associated with increased risk of $\mathrm{HCV}$ are also those which are potentially associated with increased number of lifetime injecting episodes. Each injecting episode presents a possible scenario where the sharing of injecting equipment may occur ${ }^{14}$. Research conducted in Trinity Court in 1993 found that $56 \%$ of IDU had shared syringes in the preceding six months ${ }^{15}$. The prevalence of HCV in those who commenced injecting in this decade, and thereby had access to expanded harm reduction strategies, remains high at $58.9 \%$. Although this proportion is significantly lower compared to those who began injecting earlier, multivariate analysis indicates that this finding is due to the confounding effect of shorter injecting history and could therefore not be used to support a conclusion that there has been any reduction in unsafe injecting practices. Figure 1 demonstrates the rapid acquisition of HCV after initiation into injecting. This supports the view expressed by Garfein and colleagues that those seeking to prevent spread of HCV among IDU have a very narrow window of opportunity in which to do so ${ }^{16}$. 
The small proportion of IDU demonstrating current infectivity for HBV, indicates that the pool from which HBV infection can arise is very much smaller than the corresponding pool of HCV infection. Also the fact that most services dealing with IDU in Dublin, including prisons, have a policy of actively encouraging the uptake of HBV vaccination may also be contributing to its low prevalence. Screening for the antibody markers of HBV would have yielded valuable additional information about the proportion of IDU with previous exposure to this virus ${ }^{2}$. Unfortunately, such tests were not routinely performed.

Johnson has reported a HIV prevalence of $14.8 \%$ among IDU attending a Dublin needle exchange in $1991^{17}$. The prevalence detected among our study group is very much lower $(1.2 \%)$. This reduction is striking but it must be noted that the group studied here are younger and injecting histories are shorter than the previously studied group. Our data demonstrates a sustained low prevalence of HIV among new attenders to our treatment service. In their review of cities with sustained low prevalence of HIV among IDU, Des Jarlais and colleagues have described three features which they considered important $^{5}$. These are the adoption of harm reduction strategies early, utilisation of community outreach and ensuring access to sterile injecting equipment. Dublin has indeed embraced these approaches. Nevertheless, the observed reduction in prevalence of HIV infection in those who commenced injecting in this decade may simply reflect their shorter injecting history. Ongoing monitoring of HIV test results over the coming years may clarify this issue and will provide an area for further research. 
Hepatitis C is associated with substantial morbidity and mortality ${ }^{18}$. Current harm reduction strategies appear ineffective in protecting IDU from this infection ${ }^{8,19}$. Proposed novel adaptations to these strategies will attempt to educate IDU ( or potential IDU ) during, or before, the narrow 'window of opportunity' and may in time prove beneficial ${ }^{16}$. In Europe, increasing numbers of drug misusers are being introduced to heroin through 'chasing the dragon' before possibly progressing on to injecting ${ }^{20}$. Education of this group regarding safe injecting and the risk of HCV should be considered. Overall, we believe that in Dublin, among IDU who commenced injecting in this decade, our data supports the view that hepatitis $\mathrm{C}$ will create a larger health burden than either hepatitis B or HIV/AIDS. Harm reduction approaches should adapt to this change in need. Hence, while the low prevalence of HIV must be welcomed, any decision by policy makers that funds could now be diverted away from harm reduction would be very premature.

\section{Acknowledgements}

The authors wish to acknowledge the contribution of the staff at the Virus Reference Laboratory, Dublin, where all blood tests were analysed. We also wish to thank Drs. Joe Barry, Bob McDonald and Zachary Johnson for their advice and criticism in the preparation of this manuscript. Finally, we wish to express our gratitude to Siobhan Fisher for her administrative support and to Louise McAuley and Debbie Smullen for assistance with data management. 


\section{References}

1. WHO COLLABORATIVE STUDY GROUP (1993) An international comparative study of HIV prevalence and risk behaviour among drug injectors in 13 cities, Bulletin on Narcotics, XLV, 19-46.

2. LEVINE, 0.S., VLAHOV, D.,NELSON, K.E. (1994) Epidemiology of hepatitis B virus infections among injecting drug users: Seroprevalence, risk factors and viral interactions, Epidemiologic Reviews, 16, 418-436.

3 WODAK, A. \& CROFTS, N. (1996) Once more unto the breach: controlling hepatitis $\mathrm{C}$ in injecting drug users, Addiction, 91, 181-184.

4. BRETTLE, R.P. (1991) HIV and harm reduction for injecting drug users, AIDS, $5,125-136$.

5. DES JARLAIS, D. C., HAGAN, H.,FRIEDMANN, S. R., FRIEDMANN, P., GOLDBERG, D., FRISCHER, M., GREEN, S., TUNVING, K., LJUNGBERG, B., WODAK, A. ET AL (1995) Maintaining low HIV Seroprevalence in populations of injecting drug users, Journal of the American Medical Association, 274, 1226-1231.

6. STIMSON, G. V., (1996) Has the United Kingdom averted an epidemic of HIV1 infection among drug injectors?, Addiction, 91, 1085-1088.

7. HAGAN, H., DES JARLAIS, D.C., FRIEDMAN, S.R., PURCHASE, D. \& ALTER, M.J. (1995) Reduced risk of hepatitis B and hepatitis C among injection drug users in the Tacoma syringe exchange program, American Journal of Public Health, 85, 1531-1537.

8. CROFTS, N., NIGRO, L., OMAN, K., STEVENSON, E., \& SHERMAN, J. (1997) Methadone maintenance and hepatitis C virus infection among injecting drug users, Addiction 92, 999-1005.

9. DALY, L.E., BOURKE, J.B. \& McGILVRAY, J. (1991) Interpretation and uses of medical statistics. (Oxford, England, Blackwell Scientific Publications. )

10. STIMSON, G.V., JONES, S., CHALMERS, C. \& SULLIVAN, D. (1998) A short questionnaire (IRQ) to assess injecting risk behaviour, Addiction 93, 337-347.

11. MORRISON, C.S., McCUSKER, J., STODDARD, A.S. \& BIGELOW, C. (1995) The validity of behavioral data reported by injection drug users on a clinical risk assessment, The International Journal of the Addictions, 30, 889-899. 
12. DE LAMBALLERIE, X. (1996) Serological and molecular biology screening techniques for HCV infection, Nephrology, Dialysis, Transplantation, 11 (Supplement 4), 9-11.

13. SCHREIBER, G.B., BUSCH, M.P., KLEINMAN, S.H.\& KORELITZ, J.J. (1996) The risk of transfusion transmitted viral infections. The Retrovirus Epidemiology Donor Study, New England Journal of Medicine, 334(26), 1685-1690.

14. McKEGNEY, N., ABEL, M., TAYLOR, A., FRISCHER, M., GOLDBERG, D. \& GREEN, S. (1995) The preparedness to share injecting equipment: an analysis using vignettes, Addiction, 90, 1253-1260.

15. DORMAN, A., KEENAN, E., SHUTTLER, C., MERRY, J. \& O'CONNOR, J.J. (1997) HIV risk behaviour in Irish intravenous drug misusers, Irish Journal of Medical Science, 166, 235-238.

16. GARFEIN, R.S., VLAHOV, D., GALIA, N., DOHERTY, M.C. \& NELSON, K.E. (1996) Viral infections in short-term injection drug users: the prevalence of the hepatitis $\mathrm{C}$, hepatitis $\mathrm{B}$, human immunodeficiency, and human T-lymphocyte viruses. American Journal of Public Health, 86, 655-661.

17. JOHNSON, Z., O'CONNOR, M., POMEROY, L., JOHNSON, H., BARRY, J., SCULLY, M., \& FITZPATRICK, E. (1994) Prevalence of HIV and associated risk behaviour in attendees at a Dublin needle exchange, Addiction, 89, 603-607.

18. FOSTER, G.R., GOLDIN, R.D., MAIN, J., MURRAY-LYON, I., HARGREAVES, S. \& THOMAS, H.C. (1997) Management of chronic hepatitis C: clinical audit of biopsy based management algorithm. British Medical Journal, 315, 453-458.

19. WODAK, A. (1997) Hepatitis C: waiting for the grim reaper. Medical Journal of Australia, 166, 284-285.

20. STRANG, J., GRIFFITHS P,. \& GOSSOP, M. (1997) Heroin smoking by 'chasing the dragon': origins and history. Addiction, 92, 673-683. 


\section{Statistical methods}

Data analyses were with the statistical package for the social sciences (SPSS Inc., Chicago, USA), version 7.51. For ordered categorical variables the Mantel-Haenszel chi-squared test for linear trend was used when data suggested a linear trend. The Mann-Whitney U-test was performed when the distribution of a continuous variable was skewed. For HCV, multivariate analyses were performed using logistic regression and variables found to be significant on univariate analyses were entered into the regression equation ${ }^{9}$.

Word count in this shortened version - $\quad 75$ words

Word count in submitted manuscript - $\quad 138$ Words 